\title{
Morphine-Induced Analgesic Tolerance Effect on Gene Expression of the NMDA Receptor Subunit 1 in Rat Stri- Crossuark atum and Prefrontal Cortex
}

\author{
Shamseddin Ahmadi ${ }^{{ }^{*}}$, Fatemeh Rafieenia', Jalal Rostamzadeh ${ }^{1}$
}

1. Department of Biological Science and Biotechnology, Faculty of Science, University of Kurdistan, Sanandaj, Iran.

Citrat on: Ahmadi, Sh., Rafieenia, F., \& Rostamzadeh, J. (2016). Morphine-induced analgesic tolerance effect on gene expression of the NMDA receptor subunit 1 in rat striatum and prefrontal cortex . Basic and Clinical Neuroscience, 7(3), 241-248. http://dx.doi.org/10.15412/J.BCN.03070309

: http://dx.doi.org/10.15412/J.BCN.03070309

Article info:

Received: 15 May 2015

First Revision: 04 June 2015

Accepted: 25 September 2015
Key Words:

Morphine, Gene expression, Prefrontal cortex, Corpus striatum

\begin{abstract}
A B S T RA C T
Introduction: Morphine is a potent analgesic but its continual use results in analgesic tolerance Mechanisms of this tolerance remain to be clarified. However, changes in the functions of $\mu$-opioid and N-Methyl-D-aspartate (NMDA) receptors have been proposed in morphine tolerance. We examined changes in gene expression of the NMDA receptor subunit 1 (NR1) at mRNA levels in rat striatum and prefrontal cortex (PFC) after induction of morphine tolerance.

Methods: Morphine (10 mg/kg, IP) was injected in male Wistar rats for 7 consecutive days (intervention group), but control rats received just normal saline $(1 \mathrm{~mL} / \mathrm{kg}$, IP). We used a hotplate test of analgesia to assess induction of tolerance to analgesic effects of morphine on days 1 and 8 of injections. Later, two groups of rats were sacrificed one day after 7 days of injections, their whole brains removed, and the striatum and PFC immediately dissected. Then, the NR1 gene expression was examined with a semi-quantitative RT-PCR method.
\end{abstract}

Results: The results showed that long-term morphine a administration induces tolerance to analgesic effect of the opioid, as revealed by a significant decrease in morphine-induced analgesia on day 8 compared to day 1 of the injections $(\mathrm{P}<0.001)$. The results also showed that the NR1 gene expression at mRNA level in rats tolerant to morphine was significantly increased in the striatum $(\mathrm{P}<0.01)$ but decreased in the $\mathrm{PFC}(\mathrm{P}<0.001)$.

Conclusion: Therefore, changes in the NR1 gene expression in rat striatum and PFC have a region-specific association with morphine-induced analgesic tolerance.

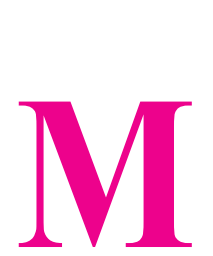

\section{Introduction}

orphine is the most effective and commonly used analgesic in the treatment of moderate to severe pain (He, Kim, \& Whistler, 2009). However, development of tolerance to the analgesic effects of morphine remains a major problem in the clinical man- agement of pain (Benyamin et al., 2008; Xu, Xu, Ma, \& Jiang, 2015). It has been suggested that long-term use of morphine induces changes in opioid receptors and subsequent signaling molecules at mRNA level (Fabian et al., 2002). There are also some reports that morphine tolerance results from a complex interplay of several events or adaptations occurring in multiple neurotransmitter systems including N-methyl-D-aspartate (NMDA) receptors

\section{* Corresponding Author:}

Shamseddin Ahmadi, PhD

Address: Department of Biological Science and Biotechnology, Faculty of Science, University of Kurdistan, Sanandaj, Iran

Tel: +98 (871) 6660075 Fax: +98 (871) 6622702

E-mail:sh.ahmadi@uok.ac.ir 
(Trujillo \& Akil, 1991a; Trujillo \& Akil, 1991b). It has been proposed that repeated injections of opioids may indirectly cause excessive activation of NMDA receptors by stimulation of $\mu$-opioid receptors (Mayer, Mao, Holt, \& Price, 1999). In addition, NMDA receptors and associated intracellular cascades have been shown to be involved in neural mechanisms of hyperalgesia induced by long-term morphine treatments (Mao, Price, Phillips, Lu, \& Mayer, 1995; Mayer, Mao, Holt, \& Price, 1999).

NMDA receptors are tetramers composed of different subunits known as NR1, NR2A-D, and NR3 A-B (Glasgow, Siegler Retchless, \& Johnson, 2015; Paoletti, 2011). The NRI subunit is an obligatory subunit of all endogenous NMDA receptors (Sanz-Clemente, Nicoll, \& Roche, 2013). According to previous research, longterm treatment with morphine alters the NR1 subunit expressions with a region specific pattern in rat brain (Zhu, Brodsky, Gorman, \& Inturrisi, 2003; Zhu et al., 1999). It has been also shown a link between morphine-mediated changes in limbic neuronal activity and changes in gene expression of NMDA receptors in these areas (Turchan, Maj, \& Przewlocka, 2003).

In addition to the cortex, limbic areas of brain, including the hypothalamus, prefrontal cortex (PFC) and striatum receive process information of nociceptive signals (Almeida, Roizenblatt, \& Tufik, 2004). It has been proposed that these areas affect emotional-affective and cognitive components of the pain sensation (Neugebauer, Galhardo, Maione, \& Mackey, 2009). Changes in expression of the NR1 subunit modulate NMDA receptor function and thereby affect the nervous system's response to noxious stimuli (Da Silva, Walder, Davidson, Wilson, \& Sluka, 2010). Forebrain structures, including the PFC, hippocampus, and striatum highly express NMDA receptors (Paoletti, 2011). Therefore, it is possible that long-term morphine treatment via affecting NMDA receptors in limbic areas has a role on the tolerance to analgesic effect of the drug. The objective of the present study was to examine the possible association between changes in the gene expression of NR1 subunit of NMDA receptors at mRNA level in the striatum and the PFC and morphine-induced analgesic tolerance.

\section{Methods}

\subsection{Subjects}

Male Wistar rats weighing 220-250 g (Pasteur Institute, Tehran, Iran) were used. They were caged in groups of 3 rats per each cage, and kept in an animal house at a constant temperature $\left(22 \pm 2^{\circ} \mathrm{C}\right)$ under $12: 12 \mathrm{~h}$ light/dark cycle (light begins at 7:00 AM). The animals had free access to food and water except during the experiments. All experiments were carried out during the light phase between 8:00 and 12:00. Each experimental group consisted of 6 rats. All procedures were performed in accordance with international guidelines for animal care and use (NIH publication No. 85-23, revised in 1985).

\subsection{Induction of morphine tolerance}

Morphine sulfate was purchased from Temad (Temad Co, Tehran, Iran). Morphine was prepared at dose of $10 \mathrm{mg} / \mathrm{mL}$ $\mathrm{kg}$ in normal saline. We injected morphine through an intraperitoneal route for 7 consecutive days to induce tolerance to its analgesic effect. A control group received only saline $(1 \mathrm{~mL} / \mathrm{kg})$, instead of morphine, during 7 days of the regimen. Treatments were done between 10:00 and 12:00.

\subsection{Hotplate test of analgesia}

Morphine-induced analgesic tolerance was examined with a hotplate test of analgesia on days 1 and 8 of the injections (first day and one day after the final injections of saline or morphine). Temperature of the hotplate was set at $52 \pm 0.1^{\circ} \mathrm{C}$, then each animal was placed on the hotplate apparatus surrounded by a glass square to prevent them from escaping (Pooya-Armaghan Co, Iran). Time between placement of rats on the hotplate and first jumping or licking one of the hind paws were recorded as an index of pain reaction latency. First, baseline latency was measured for each rat before injection of saline or morphine. Then, each rat was tested 30 minutes after the injection of saline or morphine to measure test latency on the hotplate. A cut-off time of 80 seconds was defined as a complete analgesia. Finally, the two measured latencies were converted to percentage maximum possible effect (\%MPE) using the following formula:

$\% M P E=[($ test latency-baseline latency $) /($ cut-off timebaseline latency) $] \times 100$.

\subsection{Dissection of brain areas}

Each rat after a brief anesthesia by ether was decapitated; the whole brain was quickly removed from the skull. The PFC and the striatum were immediately dissected from the whole brain on an ice-chilled sterile surface according to a method that was previously described (Chiu, Lau, Lau, So, \& Chang, 2007). In brief, whole brain was divided into two hemispheres; the PFC was dissected with a scalpel as a part of the forebrain located in front of the anterior point of the corpus callosum in each hemisphere. The striatum in each hemisphere was exposed after cutting out the diencephalon at the medial surface and it was 
punched from surrounded cortex with a curved forceps. Dissected tissues were immediately submerged in RNAlater RNA stabilization reagent (Qiagen, Venlo, The Netherlands), and incubated overnight in the reagent at $4^{\circ} \mathrm{C}$. Then, the RNAlater was drained and tissues were stored at $-70^{\circ} \mathrm{C}$ until further analysis.

\subsection{Total RNA extraction and cDNA synthesis}

Each tissue sample (70-100 mg) was homogenized for 60 seconds at a speed of $60000 \mathrm{rpm}$ (Silent Crusher S., Heidolph, Germany). Then, the homogenate was subjected to a total RNA extraction using RNX+ reagent according the manufacture's manual (Cinagen Bioscience, Tehran, Iran). Quality of total RNA extraction was examined on a $1 \%$ agarose gel to assess $28 \mathrm{~S}$ and $18 \mathrm{~S}$ ribosomal RNA bands. Concentrations of the total RNAs were also measured with a BioPhotometer (Eppendorph, Hamburg, Germany). A semi-quantitative reverse transcription-polymerase chain reaction (RT-PCR) method was used to assess gene expression (Marone, Mozzetti, De Ritis, Pierelli, \& Scambia, 2001). Reverse transcription was performed using Viva 2-step RT-PCR Kit according to manufacturer's protocol (Vivantis Technologies, Selangor Darul Ehsan, Malaysia).

\subsection{Polymerase Chain Reaction (PCR)}

The PCR was used for amplification of $\beta$-actin (as an internal standard) and NR1 genes. Primers for both genes were designed at exon-exon junctions with the following sequences: $\beta$-actin forward primer, 5-CTGGGTATGGAATCCTGTGGC-3; $\beta$-actin reverse primer, 5-CAGGAGGAGCAATGATCTTGATC-3; NR1 forward primer, 5-TGTTCAAGAGGGTGCTGATGTC-3; and NR1 reverse primer, 5-GGATGACATGGGTACCATTGTAG-3'

PCR optimizations were done to adjust PCR program with the best annealing temperature of the primers, concentration of the total RNA for cDNA synthesis, and number of PCR cycles. PCR was carried out in a reaction volume of $20 \mu \mathrm{L}$ consisting of $10 \mu \mathrm{L}$ of PCR Master Mix (Thermo Scientific, Pittsburgh PA, USA), $2 \mu \mathrm{L}$ of cDNA, $1.5 \mu \mathrm{L}$ of upstream and downstream mix of $N R 1$ primers $(10 \mu \mathrm{M}), 1 \mu \mathrm{L}$ of upstream and downstream mix of $\beta$-actin primers $(10 \mu \mathrm{M})$ and nuclease free water up to $20 \mu \mathrm{L}$. Thermal cycling was initiated with a first denaturation step of $95^{\circ} \mathrm{C}$ for 3 minutes, followed by 33 cycles of thermal cycling of $94^{\circ} \mathrm{C}$ for 30 seconds, $60^{\circ} \mathrm{C}$ for 30 seconds, $72^{\circ} \mathrm{C}$ for 30 seconds, followed by 10 -min final extension step at $72^{\circ} \mathrm{C}(\mathrm{C} 1000$ Thermal Cycler, Bio-Rad, Hercules CA, USA). The PCR products were subsequently analyzed on $2 \%$ agarose gel electrophoresis, and bands densities were quantified with densitometry using Image $\mathrm{J}$ software.
2.7. Evaluating the NR1 gene expression after morphine-induced analgesic tolerance in the striatum and the PFC

In this experiment, the association of morphine tolerance with NRI gene expression in the striatum and PFC were investigated. Two groups of rats $(n=6)$ were used. The first group as control received saline $(1 \mathrm{~mL} / \mathrm{kg}$, IP) but the second group received daily injections of morphine $(10 \mathrm{mg} / \mathrm{kg}$, IP) for 7 consecutive days, then the rats brains were extracted on day 8 (1 day after 7 days repeated injections of saline or morphine).

\subsection{Statistical analysis}

A 2-way repeated measure ANOVA was used to analyze the hotplate test data. Further pairwise comparisons were done with post hoc Holm-Sidak test. For analyzing the results of semi-quantitative RT-PCR, at first the intensities of nucleic acid bands on the agarose gel images were converted to quantitative values using Image J program. Then, the NRI gene expression values were normalized to $\beta$-actin, and finally they were set at $100 \%$ of relative gene expression for the control group. The results of gene expressions in the control and tolerant groups were compared with independent sample t-test. $\mathrm{P}<0.05$ was considered as a significant statistical level.

\section{Results}

3.1. Hotplate test revealed that long-term morphine treatment for 7 days induced analgesic tolerance

A 2-way repeated measure ANOVA was conducted to explore the effect of repeated injections (as factor A with two levels of saline or morphine), and days of hotplate test (as factor B with two levels of days 1 or 8 of injections) on antinociception. The results showed a significant effect for factor $\mathrm{A} ; \mathrm{F}(1,10)=140.37, \mathrm{P}<0.00$, factor $\mathrm{B} ; \mathrm{F}(1$, $10)=168.04, P<0.001 ;$ and interaction of both factors; $F(1$, $10)=127.94, \mathrm{P}<0.001$. Post hoc test revealed that morphine at the dose of $10 \mathrm{mg} / \mathrm{kg}$ on the first day of the injections induced a complete analgesia compared to the saline treated group but its analgesic effect on day 8 in the intervention group was significantly decreased. According to the results, on day 8 , rats receiving 7 days morphine showed tolerance to the analgesic effects of the drug (Figure 1).

\subsection{Effect of morphine tolerance on the NR1 gene} expression in the striatum

Figure 2 shows the agarose gel image indicating the NRI and $\beta$-actin genes expressions in the striatum. Analysis of the quantitative data with independent samples t-test revealed that the NRl gene expression at mRNA levels in the striatum 


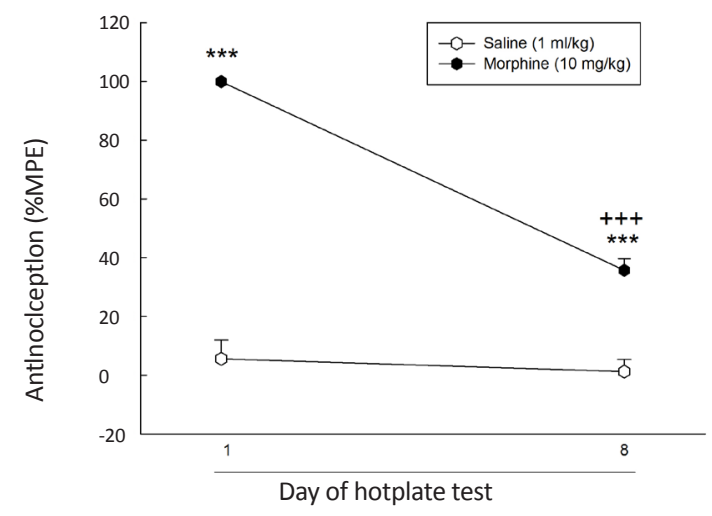

NEUR:SCIENCE

Figure 1. Long-term morphine treatment induced tolerance to its analgesic effect. Two groups of rats were used. The control group received 7 consecutive days of saline injections, and the other group received 7 days repeated injections of morphine $(10 \mathrm{mg} / \mathrm{kg})$. Both groups were submitted to hotplate test on days 1 and 8 (first day and 1 day after the final repeated injection) 30 minutes after the drug treatments. Each point represents mean \pm S.E.M. of \%MPE related to 6 rats per group.

*** $\mathrm{P}<0.001$ compared to the control group that received saline in the respective day.

$+++\mathrm{P}<0.001$ compared to the group that received morphine $10 \mathrm{mg} / \mathrm{kg}$ on day 1 .

was significantly increased $(\mathrm{P}<0.01)$ in rats that were made tolerant to morphine (Figure 3).

\subsection{Effect of morphine tolerance on the NR1 gene expression in the PFC}

Figure 4 shows the agarose gel image indicating the NRI and $\beta$-actin genes expressions in the PFC. Analysis of the quantitative data with independent samples t-test revealed that the NR1 gene expression at mRNA levels in the PFC was significantly decreased $(\mathrm{P}<0.001)$ in rats that were made tolerant to morphine (Figure 5).

\section{Discussion}

The results of the present study showed that long-term morphine administration for 7 days induced tolerance to analgesic effect of the opioid as revealed by a decrease in morphine-induced analgesia one day after the treatment. A previous study of our laboratory also confirmed efficacy of this regimen for induction of a relative tolerance to analgesic effect of morphine (Ahmadi, Amiri, Rafieenia, \& Rostamzadeh, 2013). We selected a regimen of 7 days injections as a long-term morphine treatment based on the work of Mayer et al. (1999), reported that rats receiving intrathecal administrations of morphine for 7 days showed tolerance to the analgesic effects of morphine (Mayer, Mao, Holt, \& Price, 1999). Other investigators have also used the same regimen of morphine treatment, for induction of morphine tolerance (Sepehrizadeh et al., 2008a; Sepehrizadeh et al., 2008b). However, mechanisms underlying tolerance to analgesic effect of morphine are unclear.

Changes in the expression of $\mu$-opioid receptors and related signaling molecules, at different transcriptional and/or post-transcriptional levels, have been proposed for molecular mechanisms underlying the morphine tolerance (AmmonTreiber \& Hollt, 2005; Williams et al., 2013). In addition, NMDA receptors are involved in opiate-induced analgesic tolerance and locomotor sensitization in rats (Mendez \& Trujillo, 2008). Mao (1999) suggested that NMDA receptors contribute to neuroadaptive effects of prolonged morphine administration (Mao, 1999). Bisaga et al. (2001) indicated that glutamatergic signal transduction, mediated by NMDA

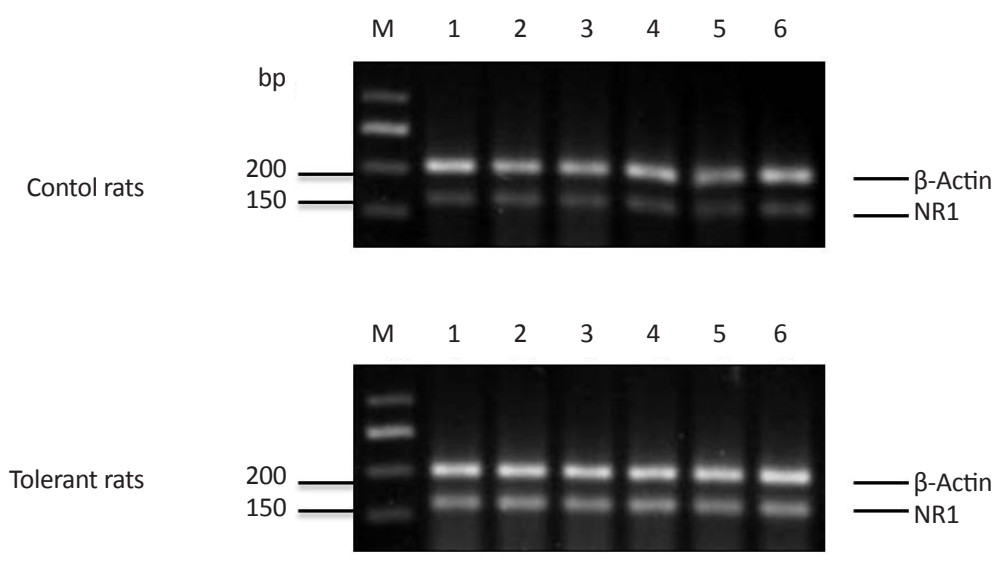

Figure 2. The agarose gel image showing band densities of the NR1 and $\beta$-actin genes after amplification with PCR. The upper panel shows bands of the NR1 and $\beta$-actin genes in the striatum of six control rats, and bands in the lower panel are related to the tolerant rats. Numbers 1 to 6 on the top of the gel images show numbers of the animals in each group. ' $\mathrm{M}$ ' symbolizes 50 bp DNA ladder. 


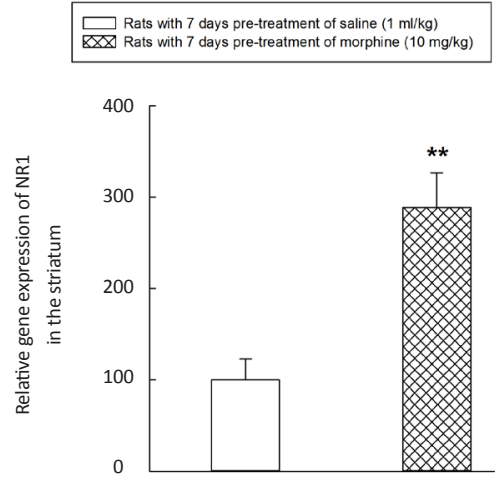

NEUR:SCIENCE

Figure 3. Relative gene expression of the NR1 gene in the striatum after induction of morphine tolerance. Each bar represents mean \pm S.E.M. of relative expression of the NR1 gene that was normalized to $\beta$-Actin and set at $100 \%$ in the control group.

** $\mathrm{P}<0.001$ compared to the control group.

receptors, are involved information and maintenance of morphine dependence in humans (Bisaga et al., 2001).

According to many studies in the field of reward and addiction, morphine via influencing mesolimbic dopaminergic system, originating from the ventral tegmental area (VTA), is able to induce neuroadaptive changes in the forebrain areas (Kelley, 2004; Le Moal \& Simon, 1991; Pierce \& Kumaresan, 2006). The forebrain areas, including the prefrontal cortex (PFC) and striatum have relatively high density of opioid receptors (Mansour, Khachaturian, Lewis, Akil, \& Watson, 1987).

Microdialysis studies have also shown that short- and long-term morphine treatment alter extracellular concen- trations of glutamate in nucleus accumbens, as a ventral part of striatum (Sepulveda, Oliva, \& Contreras, 2004), and PFC (Hao, Yang, Guo, Wu, \& Wu, 2005) by affecting the number of presynaptic glutamate receptors. The results of the present experiments showed that repeated injections of morphine for 7 days significantly increased the NR1 gene expression in the striatum but decreased it in the PFC one day after induction of morphine tolerance. According to the present results, there is an association between morphine tolerance and changes in the NRI gene expressions in the striatum and the PFC; However, this association has a region specific pattern.

It has been shown that long-term treatment with morphine alters NMDA receptors in the rat brain (Gudehithlu, Reddy, \& Bhargava, 1994). Zhu et al. (2003) reported that morphine tolerance produced a significant decrease in mRNA levels of the NRI gene in the spinal cord dorsal horn, but increased it in the nucleus raphe magnus and medial thalamus. However, they also reported that the mRNA levels of the NRI gene remained unchanged in the lateral paragigantocellular nucleus, locus coeruleus, periaqueductal grey, and sensorimotor cortex (Zhu, Brodsky, Gorman, \& Inturrisi, 2003). Furthermore, other investigators have shown that long-term exposure to morphine alters the expression of NR1 subunit in the central and basolateral nuclei of the amygdala (Turchan, Maj, \& Przewlocka, 2003).

Taken together, previous reports on expression of the NMDA receptor subunits in opiate treated animals are controversial. Some studies examining the NR1 expressions have reported either increase or no changes in its mRNA levels in the limbic areas (Lim et al., 2005; Turchan, Maj, \& Przewlocka, 2003; Zhu, Brodsky, Gorman, \& Inturrisi, 2003; Zhu et al., 1999). Studies that examined

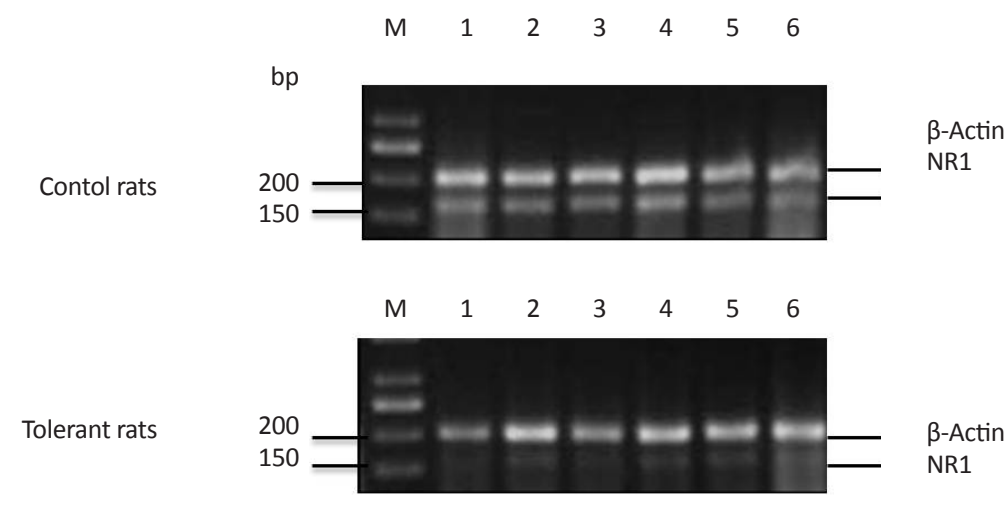

NEUR:SCIENCE

Figure 4. The agarose gel image indicating band densities of the NR1 and $\beta$-actin genes after amplification with PCR. The upper panel shows bands of the NR1 and $\beta$-actin genes in the PFC of six control rats, and bands in the lower panel are related to the tolerant rats. Numbers 1 to 6 on the top of the gel images show numbers of the animals in each group. 'M' symbolizes 50 bp DNA ladder. 


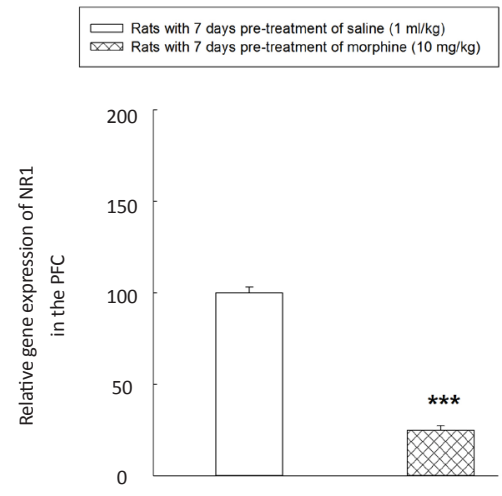

NEUR:SCIENCE

Figure 5. Relative gene expression of the NR1 gene in the PFC after morphine tolerance. Each bar represents mean \pm S.E.M. of relative expression of the NR1 gene that was normalized to $\beta$-actin and set at $100 \%$ in the control group

${ }^{* * *} \mathrm{P}<0.001$ compared to the control group.

the $N R I$ expression in the locus coeruleus and spinal cord did not reveal consistent results (Lim et al., 2005; Zhu, Brodsky, Gorman, \& Inturrisi, 2003; Zhu et al., 1999). Sepehrizadeh et al. (2008a) reported that mRNA expression of the NR1 and NR2A subunits of NMDA receptors in the striatum and PFC on 1 or 7 days after repeated administration of morphine did not significantly change compared to saline control group. It is possible that some differences in the days of morphine treatments and methods used for evaluating the gene expression account for the possible discrepancy between previous reports.

In summary, our results showed that the NR1 gene expression at mRNA level after morphine tolerance increased in the striatum but decreased in the PFC. Therefore, a link may exist between changes in the NRI gene expression in the striatum and the PFC with morphine analgesic tolerance. It is possible that long-term morphine treatment, via changes in concentrations of glutamate in striatum and PFC, affects the NRl gene expression. Although for many genes, transcript and protein levels do not correlate well (Tian et al., 2004), there are some reports that transcript level of the NR1 subunit has a correlation with its protein level (Jayanthi et al., 2014; Priya, Johar, \& Wong-Riley, 2013). Therefore, one may conclude that long-term morphine treatment alters the amount of NMDA receptors in the PFC and striatum, which may finally lead to the disruption of glutamate homeostasis and imbalances in neuronal circuits. These changes in limbic areas may, at least partly, underlie induction of tolerance to analgesic effect of morphine. However, more experiments are needed to clarify the exact mechanism of this process.

\section{References}

Ahmadi, S., Amiri, S., Rafieinia, F., \& Rostamzadeh, J. (2013) Gene expression profile of calcium/calmodulin-dependent protein kinase IIa in the rat hippocampus during morphine withdrawal. Basic and Clinical Neuroscience, 4(2), 38-44.

Almeida, T. F., Roizenblatt, S., \& Tufik, S. (2004). Afferent pain pathways: A neuroanatomical review. Brain Research, 1000(12), 40-56.

Ammon-Treiber, S., \& Hollt, V. (2005). Morphine-induced changes of gene expression in the brain. Addiction Biology, 10(1), 81-89.

Benyamin, R., Trescot, A. M., Datta, S., Buenaventura, R., Adlaka, R., \& Sehgal, N., et al. (2008). Opioid complications and side effects. Pain Physician, 11(2), 105-120.

Bisaga, A., Comer, S. D., Ward, A. S., Popik, P., Kleber, H. D., \& Fischman, M. W. (2001). The NMDA antagonist memantine attenuates the expression of opioid physical dependence in humans. Psychopharmacology, 157(1), 1-10.

Chiu, K., Lau, W. M., Lau, H. T., So, K. F., \& Chang, R. C. (2007) Micro-dissection of rat brain for RNA or protein extraction from specific brain region. Journal of Visualized Experiments, (7), 269

Da Silva, L. F., Walder, R. Y., Davidson, B. L., Wilson, S. P., \& Sluka, K. A. (2010). Changes in expression of NMDA-NR1 receptor subunits in the rostral ventromedial medulla modulate pain behaviors. Pain, 151(1), 155-161.

Fabian, G., Bozo, B., Szikszay, M., Horvath, G., Coscia, C. J., \& Szucs, M. (2002). Chronic morphine-induced changes in muopioid receptors and $\mathrm{G}$ proteins of different subcellular loci in rat brain. Journal of Pharmacology and Experimental Therapeutics, 302(2), 774-780.

Glasgow, N. G., Siegler Retchless, B., \& Johnson, J. W. (2015). Molecular bases of NMDA receptor subtype-dependent properties. Journal of Physiology, 593(1), 83-95.

Gudehithlu, K. P., Reddy, P. L., \& Bhargava, H. N. (1994). Effect of morphine tolerance and abstinence on the binding of $[3 \mathrm{H}$ MK-801 to brain regions and spinal cord of the rat. Brain Research, 639(2), 269-274.

Hao, Y., Yang, J. Y., Guo, M., Wu, C. F., \& Wu, M. F. (2005). Morphine decreases extracellular levels of glutamate in the anterior cingulate cortex: An in vivo microdialysis study in freely moving rats. Brain Research, 1040(1-2), 191-196.

He, L., Kim, J. A., \& Whistler, J. L. (2009). Biomarkers of morphine tolerance and dependence are prevented by morphineinduced endocytosis of a mutant mu-opioid receptor. FASEB Journal, 23(12), 4327-4334.

Jayanthi, S., McCoy, M. T., Chen, B., Britt, J. P., Kourrich, S., \& Yau, H. J., et al. (2014). Methamphetamine downregulates striatal glutamate receptors via diverse epigenetic mechanisms. Biological Psychiatry, 76(1), 47-56.

Kelley, A. E. (2004). Memory and addiction: shared neural circuitry and molecular mechanisms. Neuron, 44(1), 161-179.

Le Moal, M., \& Simon, H. (1991). Mesocorticolimbic dopaminergic network: Functional and regulatory roles. Physiological Reviews, 71(1), 155-234. 
Lim, G., Wang, S., Zeng, Q., Sung, B., Yang, L., \& Mao, J. (2005). Expression of spinal NMDA receptor and PKCgamma after chronic morphine is regulated by spinal glucocorticoid receptor. Journal of Neuroscience, 25(48), 11145-11154.

Mansour, A., Khachaturian, H., Lewis, M. E., Akil, H., \& Watson, S. J. (1987). Autoradiographic differentiation of mu, delta, and kappa opioid receptors in the rat forebrain and midbrain. Journal of Neuroscience, 7(8), 2445-2464.

Mao, J. (1999). NMDA and opioid receptors: their interactions in antinociception, tolerance and neuroplasticity. Brain Research Reviews, 30(3), 289-304.

Mao, J., Price, D. D., Phillips, L. L., Lu, J., \& Mayer, D. J. (1995) Increases in protein kinase $\mathrm{C}$ gamma immunoreactivity in the spinal cord of rats associated with tolerance to the analgesic effects of morphine. Brain Research, 677(2), 257-267.

Marone, M., Mozzetti, S., De Ritis, D., Pierelli, L., \& Scambia, G. (2001). Semiquantitative RT-PCR analysis to assess the expression levels of multiple transcripts from the same sample. Biological Proceduers Online, 3(1), 19-25.

Mayer, D. J., Mao, J., Holt, J., \& Price, D. D. (1999). Cellular mechanisms of neuropathic pain, morphine tolerance, and their interactions. Proceedings of the National Academy of Sciences of the United States of America, 96(14), 7731-7736.

Mendez, I. A., \& Trujillo, K. A. (2008). NMDA receptor antagonists inhibit opiate antinociceptive tolerance and locomotor sensitization in rats. Psychopharmacology (Berl), 196(3), 497-509.

Neugebauer, V., Galhardo, V., Maione, S., \& Mackey, S. C. (2009). Forebrain pain mechanisms. Brain Research Reviews, 60(1), 226242

Paoletti, P. (2011). Molecular basis of NMDA receptor functional diversity. European Journal of Neuroscience, 33(8), 1351-1365.

Pierce, R. C., \& Kumaresan, V. (2006). The mesolimbic dopamine system: the final common pathway for the reinforcing effect of drugs of abuse? Neuroscience \& Biobehavioral Reviews, 30(2), 215-238

Priya, A., Johar, K., \& Wong-Riley, M. T. (2013). Specificity protein 4 functionally regulates the transcription of NMDA receptor subunits GluN1, GluN2A, and GluN2B. Biochimica et Biophysica Acta, 1833(12), 2745-2756.

Sanz-Clemente, A., Nicoll, R. A., \& Roche, K. W. (2013). Diversity in NMDA receptor composition: many regulators, many consequences. Neuroscientist, 19(1), 62-75.

Sepehrizadeh, Z., Bahrololoumi-Shapourabadi, M., Ahmadi, S., Hashemi-Bozchlou, S., Zarrindast, M. R., \& Sahebgharani, M. (2008a). Decreased AMPA GluR2, but not GluR3, mRNA expression in rat amygdala and dorsal hippocampus following morphine-induced behavioural sensitization. Clinical and Experimental Pharmacology and Physiology, 35(11), 1321-1330.

Sepehrizadeh, Z., Sahebgharani, M., Ahmadi, S., Shapourabadi, M. B., Hashemi-Bozchlou, S., \& Zarrindast, M. R. (2008b). Morphine-induced behavioral sensitization increased the mRNA expression of NMDA receptor subunits in the rat amygdala. Pharmacology, 81(4), 333-343.

Sepulveda, J., Oliva, P., \& Contreras, E. (2004). Neurochemical changes of the extracellular concentrations of glutamate and aspartate in the nucleus accumbens of rats after chronic admin- istration of morphine. European Journal of Pharmacology, 483(23), $249-258$

Tian, Q., Stepaniants, S. B., Mao, M., Weng, L., Feetham, M. C., \& Doyle, M. J., et al. (2004). Integrated genomic and proteomic analyses of gene expression in Mammalian cells. Molecular \& Cellular Proteomics, 3(10), 960-969.

Trujillo, K. A., \& Akil, H. (1991a). The NMDA receptor antagonist MK-801 increases morphine catalepsy and lethality. Pharmacology Biochemistry \& Behavior, 38(3), 673-675.

Trujillo, K. A., \& Akil, H. (1991b). Inhibition of morphine tolerance and dependence by the NMDA receptor antagonist MK801. Science, 251(4989), 85-87.

Turchan, J., Maj, M., \& Przewlocka, B. (2003). The effect of drugs of abuse on NMDAR1 receptor expression in the rat limbic system. Drug and Alcohol Dependence, 72(2), 193-196.

Williams, J. T., Ingram, S. L., Henderson, G., Chavkin, C., von Zastrow, M., \& Schulz, S., et al. (2013). Regulation of mu-opioid receptors: Desensitization, phosphorylation, internalization and tolerance. Pharmacological Reviews, 65(1), 223-254.

Xu, H., Xu, T., Ma, X., \& Jiang, W. (2015). Involvement of neuronal TGF-beta activated kinase 1 in the development of tolerance to morphine-induced antinociception in rat spinal cord. British Journal of Pharmacology, 172(11), 2892-2904.

Zhu, H., Brodsky, M., Gorman, A. L., \& Inturrisi, C. E. (2003). Region-specific changes in NMDA receptor mRNA induced by chronic morphine treatment are prevented by the co-administration of the competitive NMDA receptor antagonist LY274614. Molecular Brain Research, 114(2), 154-162.

Zhu, H., Jang, C. G., Ma, T., Oh, S., Rockhold, R. W., \& Ho, I K. (1999). Region specific expression of NMDA receptor NR1 subunit mRNA in hypothalamus and pons following chronic morphine treatment. European Journal of Pharmacology, 365(1), 47-54. 
